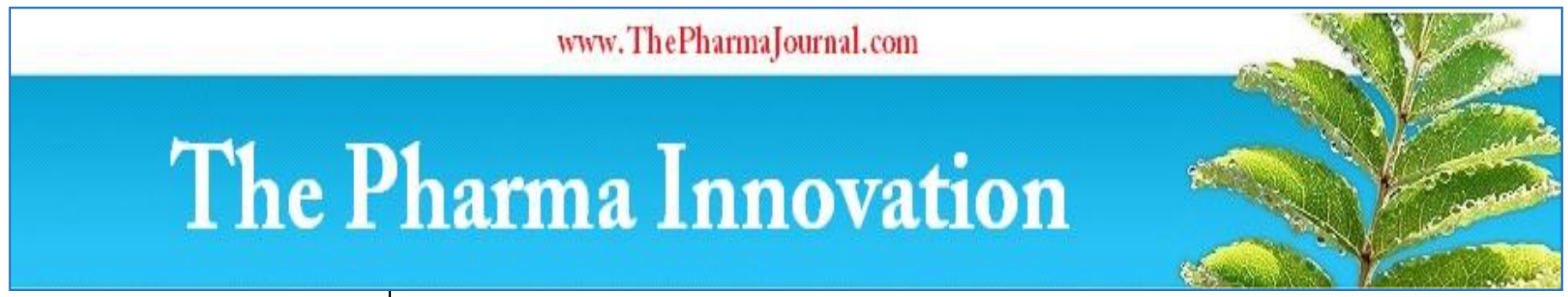

ISSN (E): $2277-7695$

ISSN (P): 2349-8242

NAAS Rating: $\mathbf{5 . 2 3}$

TPI 2021; SP-10(8): 284-288

(C) 2021 TPI

www.thepharmajournal.com

Received: 10-06-2021

Accepted: 12-07-2021

\section{Akhil Upadhyay}

Department of Entomology,

School of Agriculture, Lovely

Professional University, Punjab, India

\section{JC Hadiya}

Department of Entomology, School of Agriculture, Lovely Professional University, Punjab, India

\section{SK Gharde}

Department of Entomology, School of Agriculture, Lovely Professional University, Punjab, India

\section{Biocontrol: An effective tool for agricultural insect pests management}

\author{
Akhil Upadhyay, JC Hadiya and SK Gharde
}

DOI: https://doi.org/10.22271/tpi.2021.v10.18Se.7231

\begin{abstract}
Integrated pest control systems of insect pests used worldwide; the manipulation of important species is still a significant appliance. This review summaries the effectiveness, benefits, and protection of the use of biological agents to inhibit and control insect damage caused to crops. In general, biocontrol has been shown to be effective for plants, livestock, humans, and the ecosystem. This is in stark contrast to chemical insecticides that are more commonly used, often resulting in environmental contamination that causes damage to people and the environment. Biocontrol manufacturers continue to expand new conventions for surveying operator protection, sending and estimating the achievement of treatment. Guidelines are established by government and assembly organizations to ensure the protected and correct use of biocontrol. The benefits of organic control frameworks drive the growing option of technology. Biodiversity assurance and a high-cost share advantage are clear reasons for advancing the use of biocontrol phases. This review will help the researchers for the selection of suitable biocontrol agents for different pests and crops at various stages.
\end{abstract}

Keywords: biocontrol agent, IPM, pest, predator, parasitoids, and pathogen

\section{Introduction}

According to a recent estimate by the Union Ministry of Agriculture, in agriculture production of the field and storage is an estimated Rs 50000 crore per year by pest related damages in India, it is also reported nearly $50 \%$ of rice production is affect due to insect pests. If at least half of this loss is eliminated, it is possible to make a large amount of food and clothing available to citizens. Biological control is described as the application of an organism to suppress the total population of another organism, and it includes the control of insect pests, weeds, and diseases. DeBach described the study and use of parasites, predators, and pathogens for the regulation of host density in 1964. There is a long tradition of the use of beneficial organisms to mitigate the effects of pests. Biological control method is used to manage pests in agriculture, forestry, and greenhouse horticulture all over the world (DeBach, 1964) ${ }^{[2]}$. Ants proved productive predators of several citrus pests, according to Landis et al., $1996^{[17]}$, and the ancient Chinese augmented their populations by stealing their nests from neighboring environments and placing them in their orchards. Natural enemies play a vital role to keep the pest density below economic threshold level. Both naturally and applied biological control measures are important in the effective management of pest populations (Ignacimuthu and Jayaraj, 2002) ${ }^{[13]}$. Predatory insects and mites, as well as insects that parasitize other insects or nematodes, are used in many bio-control methods to manage insect and mite pests. Several 'microbial' agents (bacteria, viruses, and fungi) have also been produced and utilized in arthropod biocontrol (Van Lenteren, et al., 2006) ${ }^{[40]}$. Predators and parasitoids are described in the entomophagous community. Fungi, bacteria and viruses are described by entomopathogens. Natural enemy species and their hosts and prey tend to maintain an equilibrium in nature, and one group's population density depends on the density of the other

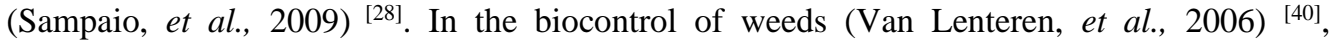
herbivorous mites and insects are also used. After the decision has been made that biological control can be a solution to the problem of pests, the objective is to classify agents that are effective in limiting target pests (Hoelmer, et al., 2005) ${ }^{[9]}$. This technology is economically feasible, has a low impact on the environment and does not pose any risk of emissions to the environment. No threats to human health or to domestic animals are present (Sampaio, et al., 2009) [28]

$2009) \cdot 284 \sim$
Corresponding Author Akhil Upadhyay

Department of Entomology, School of Agriculture, Lovely Professional University, Punjab, India 
Without proper quality control procedures, natural enemies have been made for a long time. Bad output of natural enemies has contributed to biological control failures and the low profile of these methods of pest control (Van Lenteren, 2003) [39]. If they are formed in the ecosystem, native biocontrol agents and introduced beneficial organisms are a self-renewing resource. They simply cost us whatever the takes to promote them and improve their habitat so that they can thrive. They will benefit us in maintaining our agriculture sector for as long as we keep them alive (Stoner, 1998) ${ }^{[37]}$.

\section{Approaches of Biological control}

Three general approaches to biological control are available; natural enemies are imported, supplemented, and retained. In a biocontrol program, each of these strategies can be used either alone or in combination (Landis and Orr, 1996) ${ }^{[17]}$.

\section{Importation}

The import of NE, also referred to as classical biological surveillance, is used when the target of the biocontrol programme is a pest of exotic origin (Landis and Orr, 1996) [17]. Many pests have no natural predators and are exotic. The most dramatic and sustainable way of suppressing them is always the reunification of pests with their natural enemies. Classic biological regulation is the import of certain natural enemies. Pests are increasingly being imported, either inadvertently, or in some cases, deliberately, into countries where they are not native. That most of these introductions may not develop, or if they do, the organisms may not become pests. It is not uncommon for some of these introduced species to become pests due to a lack of natural enemies to destroy their populations. The importation of NE can be highly successful in these cases (Caltagirone, 1981) ${ }^{[1]}$. Natural enemy imports began in 1911, but it was not until 1957 that a significant programme targeted at biological control of the weevil was undertaken. USDA ARS employees went out international exploration in Europe as part of this programme, which resulted in the importation of 12 parasitoid species. Six of these species have been identified and are credited with contributing in the eastern US to the reduction in the pest status of the weevil.

\section{Augmentation}

Increased biological control involves practices in which, by mass production, release of natural enemies either inoculative or inundative and invasion, natural enemy populations are increased to eliminate native or non-native pests (Orr, 2009) [21]. This can be accomplished using one or both of the following methods: mass processing and periodic invasion; or natural enemy genetic augmentation. Natural enemies are produced in insectariums and then released either inoculatively or inundatively, which is the most widely utilized method. An inoculative release every spring, for example, in places where a particular natural enemy is unable to overwinter, can allow the population to generate a pest and manage it effectively. Inundative releases include the initiation of significant amounts of a NE, so that the pest is absolutely overwhelmed by their population. When natural enemy populations are not there or cannot react rapidly enough to the pest population, augmentation is used. Therefore, augmentation does not typically include permanent suppression of pests, as may occur with methods of import or conservation (Hodek, et al., 2012) ${ }^{[8]}$.

\section{Conservation}

Biocontrol in conservation tries to identify human effects on resident natural enemies in a framework and then use those influences to increase natural enemies' ability to suppress pests (Orr, 2009) ${ }^{[21]}$. This includes determining the factors that may restrict the efficacy of a specific natural enemy and changing them to maximize the effect of the beneficial spp. Natural enemies' conservation usually entails minimizing variables that cause natural enemies to conflict or providing services that natural enemies require in their ecosystem.

(Landis, and Orr, 1996) [17]. Biological conservation regulation to protect and improve natural enemies through environmental change. These practices vary from modifying the method of using pesticides to manipulating beneficial insects' habitat within an agro-ecosystem (DeBach, 1964) ${ }^{[2]}$.

\section{Methods of biological control Natural Enemies of Pest Insects}

Natural enemies (NE) serve a critical role in reducing insect population potential. We have seen what happens when pesticides kill out potential pests' natural enemies. Insects can become destructive pests with little economic significance. Natural enemies are more likely to thrive and limit the quantity and impact of potential pest species when a non-toxic management method is applied. Predators, parasitoids, and pathogens are the three types of natural enemies of insect pests.

\section{Predators}

Insects prey on all kinds of predators. Insects are an essential food source for many animals, including birds, amphibians, reptiles, fish, and mammals. Typically, these 'insectivorous' vertebrates consume a couple of insects and only focus on a few pests unless they are in large numbers. Insects and associated predators are used more commonly for biocontrol because they feed on a less number of species of prey. Because of their shorter life cycles, these predators' population density may fluctuate in reaction to variations in prey density. Lady beetles, rove beetles, field beetles, flower bugs and other true predatory bugs, lacewings, are important insect predators. The enemies of insects and mite pests are also spiders and certain families of mites. In terms of entomophagous insect predators, the most of them are arachnids, including spiders and mites, beetles, and lacewings. Predatory mites not only decrease phytophagous mite populations, but some of them also parasitize young and adult insects or feed on insect eggs, making them potentially helpful pest control agents for insects, grasshoppers, and stored-product pests on a small scale. Spiders are diversified and efficient predators that have a significantly bigger impact on insect populations than mites, especially in tropical conditions.

\section{Parasitoids}

Parasitoids are young insects that grow and finally kill their host on or in an insect host. Adults are usually free-living and can be predators. Other tools, such as honeydew, plant nectar or pollen, can also feed on them. Many parasitoids are restricted to one or a few closely related host species because they must adapt to their hosts' life cycle, physiology, and protection. Thus, if you use parasitoids for biological control, it is critical to correctly identify the parasitoid and host species. 


\section{Pathogens}

Disease-causing bacteria, fungi, protozoans, and viruses infect insects, just as they do other animals and plants. These diseases can reduce the rate of feeding and development, as well as delayed or inhibit insect pest reproduction, or even kill them. Additionally, insects are frequently attacked by nematodes, which, along with the bacteria they carry, cause disease or death. Diseases can naturally develop and spread across an insect population under certain conditions, especially when the insect population is high. The effectiveness of entomopathogens is determined by their virulence, easy of application and development, low cost, good storage features, farmers' healthy and aesthetic accessibility, and efficacy in reducing pest issues to subeconomic levels (Jaiswal et al., 2008) ${ }^{[14]}$. Bacteria, fungi, oomycetes, viruses, and protozoa are all used in the biological control of pestiferous insects, plant diseases, and weeds (Kloepper, et al., 2004) ${ }^{[15]}$.

\section{Bacteria}

Non-spore formers, spore formers, crystalliferous and noncrystalliferous pathogens, and obligatory and optional pathogens are all terms used to describe entomopathogenic bacteria. Different genera of bacteria, such as Bacillus, Clostridium, Brevifaciens, Pseudomonas, Aerobacter, Cloaca, Proteus, Serratia, etc., have been established as entomopathogenic to date, but out of these 2 genera of the order Eubacterial (i.e., Bacillus (Bacillaceae) and Serratiae (Enterobacteriaceae)) are commonly used in insect control programmes. Bacillus thuringiensis $(B t)$ is a rod-shaped, spore-forming, gram-positive, aerobic bacteria that produces a protein crystal ( $\mathrm{Bt} \delta$-endotoxin) capable of triggering intestinal cell lysis when consumed by susceptible insects during the development of bacterial spores (Gill, et al., 1992) [6]. The $\delta$-endotoxin is a host-specific toxin that can kill a

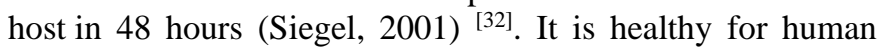
beings, beneficial species, and the environment and does not affect vertebrates (Lacey, and Siegel, 2000) ${ }^{[16]}$. Microbial $B t$ biopesticides are made up of a mass of bacterial spores and $\delta$ endotoxin crystals that are manufactured in fermentation tanks and formed as a sprayable product. $B t$ sprays are a rising technology for pest management in fruit and vegetable crops, where their high level of selectivity and protection is desired and resistance to synthetic insecticides is a problem (Van Driesche et al., 2008) ${ }^{[38]}$. Bt sprays have also been employed on broad-acre crops like maize, soybeans, and cotton, though transgenic $B t$ crops have recently supplanted them.

\section{Virus}

Entomopathogenic organisms have been identified as viruses belonging to the families Baculoviridae, Reaviridae, Iridoviridae, Poxviridae, Parovo-viridae, Picnaviridae, and Rhabdoviridae (Zhang, et al., 2007) ${ }^{[43]}$. Nuclear polyhedrosis viruses (NPV), granulosis viruses $(\mathrm{GV})$ from the Baculoviridae family, and cytoplasmic polyhedrosis viruses from the Reaviridae family, from the other side, are commonly utilised to manage a variety of insect pests (Demir, et al., 2008) ${ }^{[3]}$. Furthermore, using these biocontrol agents in combination with suitable chemical pesticides is far more successful than using one of the two controls alone (Shanmugam, et al., 2006) [31]. The virus is consumed by plant-based insects. After absorption in the midgut, the proteinaceous inundative is introduced to digestive enzymes at a high $\mathrm{pH}$ and is quickly solubilized, releasing contagious virions. Once the viral particles are released, the nucleocapsid envelope bonds with the microvilliar membrane of the gut wall cells. The nucleocapsids are released to reach the nucleus, where viral DNA can replicate and spread to other tissues like the fat body and hemolymph.

\section{Fungi}

The use of fungus to reduce insect density in biological processes to reduce disease-producing activity and, as a result, crop damage is known as mycobiocontrol (Sandhu, et al., 2012) ${ }^{[29]}$. It may affect all classes of insects, and fungi have been identified as pathogens in over 700 species. As entomopathogenic fungal pathogens, members of Deuteromycetes, Zygomycetes, Chytridiomycetes, Oomycetes, and Trichomycetes are commonly utilized (Purwar, and Sachan, 2006) ${ }^{[26]}$. Beauveria, Metarhizium sp., Nomuraea spp., Verticellium spp., and Hirsutella sp., however, are Exhibiting insecticidal behaviour against various pests of the Coleoptera, Lepidoptera, Orthoptera and Diptera orders (Ferron, 1978) ${ }^{[5]}$. Some of these fungi have narrow host ranges (for example, Aschersonia aleyrodes only infects scale insects and whiteflies), but others have a broader host range, with isolates being more specialised to target pests. Aspergillus and Fusarium are examples of facultative generalist pathogens. The majority of species, on the other hand, are obligate pathogens that are typically particular and only found in a few places (e.g., many species of Cordyceps). $M$. anisopliae, for example, is an entomopathogen. For the efficient usage of entomopathogenic fungi under field circumstances for spore production and viability, saturated or near saturated humidity in the atmosphere or water film is required (Parker, et al., 2000) ${ }^{[23]}$. Entomopathogenic fungi (EPN) are important because they are pathogenic, infection through contact, and persist in the environment for extended periods of time. In liquid or solid media, these can be mass produced. Because most entomopathogenic fungi are elective parasites that live as saprotrophs, they can be produced without living hosts. Only a few varieties of parasites are required to be raised in living hosts.

\section{a. Protozoans}

Protozoa is divided into seven phyla, and parasites of invertebrates have been found to be members of four phyla Ciliophora, Sarcomastigophora, Apicomplexa, and Microspora. When resistant spores are swallowed, the infection occurs in insects. In the guts of insect hosts, the spores produce polar tubes that permeate the intestinal epithelial cells and allow infective sporoplasm to pass through. The infective agent grows in the cytoplasm of the cell, eventually producing more spores that infect other cells. The host insect may cause a lack of vigour, a drop in the number and length of matings, a fall in fertility, and a change in behaviour after a certain degree of tissue infection, which may occur many days or even weeks before death. Protozoan insecticides are practically uneconomical and thus not practical due to their high production costs. Protozoans are also undesirable as biopesticides due to their limited pathogenicity and difficulty in large-scale manufacturing (Srivastava, 2004) ${ }^{[35]}$.

\section{b. Nematodes}

Deladinus siricidicola was the first (EPN) entamopathogenic nematode utilised for insect control. Many EPNs have since been discovered, however those belonging to the 
Steinernematidae, Heterorhabditidae, and Mermithidae families are the most effective at killing their insect hosts (Waterhouse and Norris, 1987) ${ }^{[41]}$. Terrestrial insect hosts are linked with symbiotic bacteria in the first two families, and they kill their insect hosts by septicemia. Aquatic nematodes belong to the third family, and they destroy their hosts when they depart through the cuticle. The infectious stage is a third stage juvenile, consumed with food by the host insect. They moult in the gut, penetrate the foregut, and reach the hemocoel, where they mate. Males are dying, while females are transforming into gravid worms. Eggs develop within the female and juveniles consume the mother's tissue until they flee into the hemocoel of the hosts Nematode infective stages can only live in high-humidity environments, therefore infections in nature typically occur in wet environments. As a result, high humidity is a limiting factor in their ability to thrive in cryptic and soil habitats (Srivastava, 2004) ${ }^{[35]}$.

\section{Botanicals}

Plants that protect themselves against herbivores have evolved a wide range of secondary metabolites. These substances contain phenolic compounds (e.g., tannins), glucosinolates (e.g., mustard oil), and terpenoids (e.g., mustard oil) (volatile oils, e.g., limonene). In the United States, almost 50 different botanical active compounds are recognised as plant protection products, whereas only 11 are registered in the European Union. Plant-based pesticides usually function in one of two ways: stomach poison or touch poison. There have been nearly 300 plant species investigated, with 2121 being utilised for pest management, 1005 being insecticidal, 384 being antifeedants, 297 being repellents, 27 being attractants, and 31 being growth inhibitors (Purohit and Vyas, 2004) ${ }^{[25] .}$

\section{Agricultural antibiotics}

Antibiotics are active biomolecules derived from diverse microorganisms (bacteria, fungi, and actinomycetes). A few antibiotics can also be found in plants. Antibiotics kill pathogens, disease-causing dangerous microorganisms, by interfering with their molecular processes such as transcription, translation, and so on, or by suppressing pathogen survival processes such as cell wall construction, among others. Antibiotics are divided into two types: narrowspectrum antibiotics and broad-spectrum antibiotics. Antibiotics can be taken orally or injected intravenously. Antibiotics are utilized in agriculture in a variety of ways. Validamycin, Ivermectin, Polyoxin, Zhongshengmycin, Wuyimycin, and Agricultural Antibiotic 120 are some of the antibiotics that have been discovered.

\section{Insect sex pheromone}

Females release sex pheromones for the purpose of attract men for mating, and the females do that for sexual reproduction. Sex pheromones are used for breeding and enticing the opposite sex, as well as transmitting information about the male's species, sex, age, and genotype after he is released. Defensive pheromones or sex pheromones are volatile pheromones that have a distinct odour and are focused on alarm sensitivity (Regnier and Law, 1968) ${ }^{[27]}$.

\section{Application of insect sex pheromone}

In practical pest management, pheromones are employed in the following ways: Pheromones are used to detect insecticide resistance through surveying and monitoring. It is simple to determine insecticide resistance using pheromones. Pheromones are utilized to attract pests to an area that has been poisoned or treated with insecticide. Mass trapping and pheromones are also utilised to attract the pests for the purpose of sterilize them.

\section{Importance of biopesticides in organic agriculture}

Organic farming is a method of producing agricultural products such as food and fibre. The fundamental goal of organic farming is to create biological diversity in the field for the purpose of disturb pest species' habitats and to purposefully protect and renew soil fertility. In organic agriculture, biopesticides are employed to control pest populations. Different components of plants, such as chilli and garlic, are employed to control hazardous organisms or pests due to their strong odour against insects. Basil is used as a mosquito repellent, among other things. Biopesticides have a promising future in organic agriculture (Sarkar, 2009) ${ }^{[30]}$.

\section{Conclusion}

In addition to being an alternative to insecticides, bio-control agents are environmentally friendly. Biocontrol agents minimize the selection pressure caused by pesticides, although they have significant limits. The annual habitat of cotton, for example, makes the use of insecticides a requirement for biocontrol agents to have an impact on cotton pests' subsistence, and the complexity of cotton pests makes the use of insecticides a must for biocontrol agents to influence their sustenance. Furthermore, because of the sluggish action of biocontrol agents and their responsiveness to environmental conditions, they are less suited than insecticides. As numerous unexpected ecological effects of exotic species have come to light and several large, dominant natural enemies of pests have been recognised as invasive species, the significance of biocontrol agents in biocontrol programmes has also declined. Biocontrol agents have a short shelf life, which makes storage and quality control difficult.

\section{Reference}

1. Caltagirone LE. Landmark examples in classical biological control. Annual Review of Entomology 1981;26(1):213-232.

2. DeBach P. Biological control of insect pests and weeds. London, UK: Chapman and Hall 1964.

3. Demir I, Nalcacoglu R, Demirbag Z. The significance of insect viruses in biotechnology. Tarim Bilimleri Dergisi, 2008;14:193-201.

4. Eilenberg J, Enkegaard A, Vestergaard S, Jensen B. Biocontrol of pests on plant crops in Denmark: present status and future potential. Biocontrol Science and Technology 2000;10:703-716.

5. Ferron P. Biological control of insect pests by entomogenous fungi. Annual Review of Entomology, 1978;16:259-263.

6. Gill SS, Cowles EA, Pietrantonio PV. The mode of action of Bacillus thuringiensis endotoxins. Annual Review of Entomology 1992;37:615-636.

7. Harris P. Environmental impact of introduced biological control agents. In: Mackauer, Ehler, L.E., Roland, J. (Eds.), Critical Issues in Biological Control. Intercept, Andover, Hants, UK, 1990, 289-300.

8. Hodek I, VanEmden HF, Honek A. Ecology and Behavior of the Ladybird Beetles (Coccinellidae). Black well Publishing Limited, UK 2012, 600. 
9. Hoelmer KA, Kirk AA. Selecting arthropod biological control agents against arthropod pests: Can the science be improved to decrease the risk of releasing ineffective agents? Biological control 2005;34(3):255-264.

10. Hokkanen H, Pimentel D. New approach for selecting biological control agents. The Canadian Entomologist, 1984;116:1109-1121.

11. Hussey NT, Bravenboer L. Control of pests in glasshouse culture by the introduction of natural enemies. Biological Control 1971, 195-216.

12. Hussey NW, Scopes N. Biological pest control: the glasshouse experience. Cornell Univ. Press, Ithaca 1985.

13. Ignacimuthu S, Jayaraj S. Biological control of insect pests. Journal of Scientific And Industrial Research, 2002;61(7):543-546.

14. Jaiswal AK, Bhattacharya A, Kumar S, Singh JP. Evaluation of Bacillus thuringiensis Berliner subsp. kurstaki for management of lepidopteran pests of lac insect. Entomon 2008;33:65-69.

15. Kloepper JW, Ryu CM, Zhang S. Induced systemic resistance and promotion of plant growth by Bacillus spp. Phytopathology 2004;94(11):1259-1266.

16. Lacey LA, Siegel JP. Safety and ecotoxicology of entomopathogenic bacteria. In: Charles, J.F., Delecluse, A., Nielsen-LeRoux, C. (Eds.), Entomopathogenic Bacteria: from Laboratory to Field Application. Kluwer Academic Press, Dordrecht, The Netherlands 2000, 253273.

17. Landis DA, Orr DB. Biological control: approaches and applications 1996.

18. McEvoy PB, Coombs EM. Why things bite back: unintended consequences of biological weed control. In: Follett, P.A., Duan, J.J. (Eds.), Nontarget Effects of Biological Control. Kluwer Academic Publishers, Boston, MA 2000, 167-194.

19. Myers JH, Higgins C, Kovacs E. How many insect species are necessary for the biological control of insects. Environmental Entomology 1989;18:541-547.

20. Omkar, Kumar B. Biocontrol of Insect Pests. Ecofriendly Pest Management for Food Security 2016, 25-61.

21. Orr D. Biological control and integrated pest management. In Integrated pest management: innovationdevelopment process. Springer, Dordrecht. 2009, 207239.

22. Paredes D, Cayuela L, Gurr GM, Campos M. Is ground cover vegetation an effective biological control enhancement strategy against olive pests? PLoS One 2015;10(2):e0117265.

23. Parker BL, Skinner M, Brownbridge M, El-Bouhssini M. Control of insect pests with entomopathogenic fungi. Arab Journal of Plant Protection 2000;18:133-138.

24. Parrella ML. Biological pest control in ornamentals: status and perspectives. SROP/WPRS Bull. 1990;XIII/5:161-168.

25. Purohit SS, Vyas SP. Medicinal Plant Cultivation: A Scientific Approach: Including Processing and Financial Guidelines. India. Agrobios 2004.

26. Purwar JP, Sachan GC. Insect pest management through entomogenous fungi: a review. Journal of Applied Bioscience, 2006;32:1-26.

27. Regnier FE, Law JH. Insect pheromones. The Journal of Lipid Research, 1968;9(5):541-551.

28. Sampaio MV, Bueno VHP, Silveira LCP, Auad AM. Biological control of insect pests in the tropics. Tropical
Biology and Conservation Management. Eolss Publishers, Oxford, United Kingdom 2009, 28-70.

29. Sandhu SS, Sharma AK, Beniwal V, Goel G, Batra P, Kumar A et al. Myco-biocontrol of insect pests: factors involved, mechanism, and regulation. Journal of Pathogens 2012, 1-10.

30. Sarkar NC. Role of biopesticides in organic farming. International Journal of Agriculture Environment and Biotechnology 2009;2(1):102-104.

31. Shanmugam PS, Balagurunathan R, Sathiah N. Biointensive integrated pest management for Bt. cotton. International Journal of Zoological Research, 2006;2:116-122.

32. Siegel JP. The mammalian safety of Bacillus thuringiensis-based insecticides. Journal of Invertebrate Pathology 2001;77(1):13-21.

33. Smith RF, Mittler TE, Smith CN. History of Entomology. Annual Reviews Inc., Palo Alto, California 1973.

34. Spadaro D, Gullino ML. State of the art and future prospects of the biological control of postharvest diseases. International Journal of Food Microbiology, 2004;91:185-194.

35. Srivastava KP. A Textbook of Applied Entomology (Methods of Insect Pest Control), vol. I. Kalayani Publishers, New Delhi 2004.

36. Steenis MV. Biological control of the cotton aphid, Aphis gossypii Glover (Homoptera: Aphididae): Preintroduction evaluation of natural enemies. Journal of Applied Entomology 1992;114(1-5):362-380.

37. Stoner K. Approaches to the biological control of insects. Ellsworth: University of Maine Cooperative Extension 1998.

38. Van Driesche R, Hoddle M, Center T. Control of Pests and Weeds by Natural Enemies: An Introduction to Biological Control. Blackwell Publishing, Oxford, UK 2008.

39. VanLenteren JC. Quality control of natural enemies: where are we and where do we go? Iobc WPRS Bulletin, 2003;26(10):171-176.

40. VanLenteren JC, Bale JS, Bigler F, Hokkanen HMT, Loomans AJM. Assessing risks of releasing exotic biological control agents of arthropod pests. Annual Review of Entomology 2006a;51:609-634.

41. Waterhouse DF, Norris KR. Know your crop. It's pest problem and control. Pesticides 1987b;7:77-81.

42. Wilson F, Huffaker CB. The philosophy, scope and importance of biological control. In: Huffaker, C.B., Messenger, P.S. (Eds.), Theory and Practice of Biological Control. Academic Press 1976, 788.

43. Zhang Y, Qu LJ, Wang YZ. Using virus to restore and construct table forest ecosystem for pest insects control. Chinese Forest Science Technology 2007;6:53-61. 